\title{
Protecting free-living dormice: molecular identification of cestode parasites in captive dormice (Muscardinus avellanarius) destined for reintroduction
}

\begin{abstract}
The success of any population translocation programme relies heavily on the measures implemented to control and monitor the spread of disease. Without these measures, programmes run the risk of releasing immunologically naïve species or, more dangerously, introducing novel infectious agents to native populations. As a precaution, a reintroduction programme for the common or hazel dormouse, Muscardinus avellanarius, in England screens dormice before release following captive breeding. Using PCR sequencing of a range of genes, we tested whether the same species of tapeworm(s) were present in captive and free-living dormice. While only Rodentolepis straminea were identified in free-living dormice, cestode ova found in a captive individual produced a molecular match closely related to Hymenolepis microstoma and a previously unrecorded Rodentolepis species. To prevent putting at risk the free-living population, we recommended the continued treatment of dormice showing tapeworm infection before release. Our work demonstrates how molecular techniques can be used to inform reintroduction programmes, reduce risk from disease and increase chances of reintroduction success.
\end{abstract}




\section{Protecting free-living dormice: molecular identification of cestode parasites in captive dormice (Muscardinus avellanarius) destined for reintroduction}

\section{Introduction and purpose}

Interventions attempting to recover or reduce the loss of populations at risk of extinction have led to an increase in animal and plant translocations in the last 35 years (Seddon et al. 2007). Defined by Soorae (2008) as the deliberate, human-mediated movement of individuals or populations from one location to another, translocations have had many successful attempts, such as the Arabian Oryx (Oryx leucoryx) (Price 1989), the red kite (Milvus milvus) (Carter 2001) and the Californian condor (Gymnogyps californianus) (Toone and Wallace 1994). However, these translocations often consist of small, isolated groups of individuals, factors that increase the risk of disease which may in turn reduce the chances of success of a reintroduction programme (Viggers 1993). For example, the failure of the reintroduction of the midwife toad, (Alytes obstetricans) in Mallorca, Spain has been linked to an alien pathogen, Batrachochytrium dendrobatidis. This pathogen was contracted in captivity and, through the release programme, introduced into free-living populations leading to major disease outbreaks (Walker et al. 2008). Parasites introduced with a translocated host are often considered to be important causes of disease emergence, producing high morbidity and mortality in native hosts (Lymbery et al. 2014). In the face of unknown parasites or strains of parasites, hosts' immune systems may fail to make an effective response. For example, the squirrelpox virus was inadvertently introduced to the UK with the introduction of grey squirrels (Sciurus carolinensis) in the 1870s. This lead to the decimation of red squirrel (Sciurus vulgaris) populations (Sainsbury et al. 2008) and still continues to affect their numbers. Likewise, varroasis, a disease of honeybees caused by the mite Varroa jacobsoni, has spread globally (except Australia, New Zealand and Central Africa) after the European honeybee (Apis mellifera) was introduced into Asia 
(Oldroyd 1999). Although translocations are necessary for effective conservation, without proper disease screening and monitoring, they could do more damage than good.

The common or hazel dormouse, Muscardinus avellanarius, is a protected species under both United Kingdom and European law and has suffered major historical decline in the United Kingdom (Bright et al. 1996). It has been suggested that the decline is due to the loss and deterioration of suitable habitat, population fragmentation, as well as wider climatic changes (Bright et al. 1996, 2006; Mitchell-Jones and White 2009). The dormouse has declined in both numbers and distribution, and recent surveys indicate the species occupies only half of its former distributional range since 1885 (Bright et al. 2006). In 1992, Natural England (NE) and the People's Trust for Endangered Species (PTES) launched a recovery programme for the species. The central aims of the programme were habitat management, captive breeding and the reintroduction of dormice to areas of England and Wales where natural re-colonisation was unlikely (Mitchell-Jones and White 2009). Seven years after the programme started it was suggested that the then new recommendations for health monitoring of animals, produced by the International Union for Conservation of Nature (IUCN 1998), should be followed. These guidelines aim, among other things, to help protect reintroduced individuals and wild populations from alien pathogens. Preferably the preparation of a full disease risk analysis (DRA) (Cunningham 1996; Sainsbury et al. 2012; Viggers et al. 1993; Woodford and Rossiter 1993) is recommended before a reintroduction is carried out to identify and address specific risks. However, since the dormouse recovery programme was already in progress a full DRA would not have been possible and instead a health screening protocol was implemented.

Helminth screening via faecal examination in 1999 revealed the presence of tapeworm eggs in captive dormice, which were identified by microscopy as either Rodentolepis fraterna or $R$. straminea (pers. com. RA Bray 2000). These flatworm parasites (Platyhelminthes: Cestoda) are common in many rodents, but were not previously detected in wild dormice in the UK. Heavy burdens of $R$. fraterna have been linked to greater mortality in a captive spinifex hopping mouse (Notomys alexis) colony native to Australia (Hill at al. 2007), a parasite that is reported to be present in free-living N. alexis and other wild native Muridae 
(Vaucher, Beveridge, \& Spratt, 1984). These findings raised concerns that similar adverse effects could occur in wild dormice populations if exposed to this parasite. As such, it has since been protocol for dormice showing helminthic infection to be held in quarantine and treated to eliminate hookworms, roundworms and tapeworms (cestodes) prior to reintroduction. It was unclear, however, whether this removal was necessary for safeguarding the free-living populations or if it was not merely burdening the programme with removal of naturally occurring parasites (Gomez et al. 2012). Brown (2008), when investigating the intestinal fauna of wild dormice in the UK, found no significant differences in cestode prevalence $(15.05 \%, \mathrm{n}=93$ and $19.53 \%, \mathrm{n}=31)$ for pre-existing and reintroduced populations respectively. This study, however, used microscopic identification which was unable to resolve below the family level all cestodes were either reported as members of the Hymenolepididae or of an unidentifiable family - and was therefore unable to determine whether the identities of helminths differed between the two populations.

In this study, we wanted to test whether the cestodes found in captive and free-living dormice were distinct species. Faecal samples originating from pre-released quarantined dormice and from free-living dormice populations in England and Wales, were screened for the presence of cestodes. Using molecular and phylogenetic techniques, we then determined whether the helminth infections in these two groups were distinct.

\section{Methods}

\section{The dormouse reintroduction programme}

The dormice destined for reintroduction are bred by 13 licenced breeders who are members of the Common Dormouse Captive Breeders Group (CDCBG). Breeders follow a studbook in order to limit inbreeding, facilitate transfer of genetically important individuals between collections and facilitate pairing and breeding of wild caught or first generation individuals (Forder 2006). Prior to reintroduction dormice are held in quarantine at either Paignton Zoo (PZ) or the Zoological Society of London (ZSL) for 
a period of approximately two months before release. During these two months, animals are kept under strict quarantine barriers and their body weight and health are closely monitored.

\section{Sample collection}

During the quarantine period individuals or breeding pairs were kept in separate enclosures, under strict hygiene barriers from other species. Samples were collected from each consignment of dormice on a minimum of three occasions: once on arrival at the quarantine site and twice during the quarantine period (day 21 and day 28). If a cestode positive sample was detected, the individual would be treated to eliminate the parasite and the sampling cycle would recommence. Animals were required to produce three faecal samples free of cestodes before release. All samples were submitted for parasitology screening and, to ensure the collection of fresh faeces, the cage was cleaned the day before sampling according to the quarantine protocol (Peniche and Sainsbury 2014). All faecal pellets found were collected and one faecal pot per cage was submitted to the microbiology laboratory at ZSL London Zoo for examination by light microscopy. Any samples that tested positive for cestode eggs were kept in Sigma Aldrich RNA later ${ }^{\mathrm{TM}}$ or $70 \%$ ethanol.

Free-living dormice faecal samples (N=213) were collected opportunistically between 2009 and 2013 through the UK National Dormouse Monitoring Programme surveys (White 2012). Samples were collected from 14 reintroduced and 16 naturally existing locations across 15 counties from Wales and England and were stored in $70 \%$ ethanol.

\section{DNA extraction, amplification and sequencing}

DNA from all samples that tested positive for cestode eggs under microscopic examination was extracted from the stored faeces following the Qiagen QIAamp DNA Stool Mini Kit® protocol for pathogen detection. The obtained eluate of $60 \mathrm{ul}$ of genomic DNA was stored at $-20 \mathrm{C}$ until targeted amplification was performed. Primers for the amplification of the internal transcribed spacer 1 (ITS1) region were 
designed by Macnish et al. (2002) and primers for the amplification of the small subunit (18S) and large subunit (28S), were taken from Littlewood and Olson (2001) (Table 1).

For PCR amplification of the ITS sequence we used $12 \mu \mathrm{l}$ of Qiagen HotStarTaq Master Mix®, 7.5ul RNase free water, $2 \mu \mathrm{l}$ of each primer at $0.02 \mathrm{mM}$ and $2.5 \mu$ lof template DNA at $10 \mathrm{ng} / \mathrm{ul}$ per sample. The thermal cycler was set for activation at $15 \mathrm{~min} 95 \mathrm{C}, 45$ cycles $(30 \mathrm{sec} 94 \mathrm{C}$, annealing 90sec $60 \mathrm{C}$ and $60 \mathrm{sec}$ $72 \mathrm{C}$ ) and extension of 30min 60C. For the PCR amplification of the $18 \mathrm{~S}$ sequences (primers $600 \mathrm{~F} / \mathrm{A} 27$ and wormA/1270R) and the $28 \mathrm{~S}$ sequences (primers $300 \mathrm{~F} / 400 \mathrm{R}$ ) we used $0.2 \mathrm{ul}$ of $5 \mathrm{u} / \mathrm{ul}$ of Promega Gotaq ${ }^{\circledR}, 4 \mathrm{ul} 5 \mathrm{x}$ reaction buffer, $2 \mathrm{ul}$ of $10 \mathrm{mM}$ dNTP's, $1.2 \mathrm{ul} 25 \mathrm{mM} \mathrm{MgCl}_{2}, 1 \mathrm{ul}$ of each primer at $10 \mathrm{mM}$, 9.6ul Rnase free water, and $1 \mu$ lof template DNA at $10 \mathrm{ng} / \mathrm{ul}$ per sample. The thermal cycler was set for $3 \mathrm{~min} 94 \mathrm{C}$, 40 cycles ( $30 \mathrm{sec} 94 \mathrm{C}$, annealing $30 \mathrm{sec} 56 \mathrm{C}$ and $2 \mathrm{~min} 72 \mathrm{C}$ ) and extension of $7 \mathrm{~min} 72 \mathrm{C}$. For the PCR amplification of the $18 \mathrm{~S}$ sequences with primers 930F and Cestode6 we used 6.2 $\mu$ lof Qiagen HotStarTaq Master Mix ${ }^{\circledR}, 2.8$ ul Rnase free water, $1.5 \mu$ lof each primer at $0.02 \mathrm{mM}$ and $1 \mu$ lof template DNA at $10 \mathrm{ng} / \mathrm{ul}$ per sample. The thermal cycler settings remained unchanged. PCR products were visualised on an agarose gel and positive products were submitted for Sanger sequencing using the same PCR primers. Forward and reverse sequences were edited using Geneious version 7.1.7 (Kearse et al. 2012) and consensus sequences constructed. The consensus sequences were screened against the GenBank $^{\circledR}$ database using the tblastn algorithm.

\section{Phylogenetic analysis}

We used the amplified sequences of $18 \mathrm{~S}$ and $28 \mathrm{~S}$ to generate phylogenetic trees. To gather homologous sequences for related species, we BLAST searched each amplified sequence against GenBank ${ }^{\circledR}$ (Benson et al. 2012), limiting the searches to the tapeworm order Cyclophyllidea (NCBI ID: 6201). For each BLAST search we downloaded the sequence records of all top 100 matching results, ordered by e-value. In total we downloaded 300 and 200 sequences for the three amplified sections of $18 \mathrm{~S}$ and the two amplified sections of $28 \mathrm{~S}$ respectively. Outgroup sequences, used to root resulting trees, were also 
retrieved by BLAST searching for the best matching sequences for species in the tapeworm order Caryophyllidea as this taxon is both outside of the Cyclophyllidea and occupies a comparatively basal phylogenetic position in the tapeworm tree (Olson et al. 2008).

Each amplified sequence and its set of BLAST results were aligned using MAFFT (v7, Katoh and Standley 2013) with the structural informative QINSI algorithm as all sequences were ribosomal RNA. The resulting alignments were trimmed by removing all non-overlapping flanking sequences. To generate phylogenies, we concatenated the alignments of the amplified sequences for the $18 \mathrm{~S}$ and $28 \mathrm{~S}$ genes. In total, we created three concatenated alignments: two sequence-level alignments for the $18 \mathrm{~S}$ and $28 \mathrm{~S}$ genes separately and one combined species-level alignment of both $18 \mathrm{~S}$ and $28 \mathrm{~S}$ alignments. Because not all IDs and species will necessarily have amplified sequences covering the entire length of the concatenated alignment, we introduced gaps whenever a section was unrepresented. For the $18 \mathrm{~S}$ alignment, we allowed IDs to have missing sequence in only one of the three amplified sections. This produced an alignment of 3,276 nucleotides representing 101 species with a mean 45 missing section gaps per species. For the $28 \mathrm{~S}$ alignment, we did not allow any gaps. This resulted in an alignment of 1,198 nucleotides representing 68 species. For the combined alignment of $18 \mathrm{~S}$ and $28 \mathrm{~S}$ sequences, we maximised the number of possible species in the tree by allowing up to two sections to not be represented, producing an alignment of 4,474 nucleotides representing 59 species and containing a mean 984 missing section gaps per species.

To generate the phylogenies we used RaxML (v7, Stamatakis 2006) with a GTRCAT model for concatenated alignments representing over 100 species and a GTRGAMMA model for super-matrices representing fewer than 100 . For the combined alignment of $18 \mathrm{~S}$ and $28 \mathrm{~S}$, we used gene partitioning to account for rate differences between genes. To assess nodal support we performed a bootstrap analysis with RaxML using 100 replicates all with different starting trees. We report the consensus tree of nodes with support over $50 \%$. All trees were rooted, with the exception of the $28 \mathrm{~S}$ gene tree for which homologous Caryophyllidea sequence could not be found for all amplified sequences. 


\section{Results}

\section{Captive dormouse screening}

In 1999 the dormouse reintroduction programme health screening protocol revealed a single captive bred dormouse harbouring cestode eggs and adult worms were found when examined post mortem.

Regrettably, the post mortem report was no longer available to the authors at the time when this script was prepared. The adult tapeworms were stained and mounted, then identified as being either Rodentolepis straminea or R. fraterna (pers.com. RA Bray 2000) but unfortunately no material was collected for molecular analysis. In 2009, three faecal samples from a single quarantined individual contained cestode eggs. These were processed for parasite analysis and a consensus sequence of 566 bp (KU840382) was obtained from the amplification of the ITS1 region. This produced an $85.7 \%$ identity match to Hymenolepis microstoma AY221158. From the same sample, three sequences were obtained for the 18S region (5' and 3' strands of 343 (KU840384), 640 (KU840385) and 780 bps (KU840383) in length). These sequences, when blasted, returned $95.2 \%, 96.8 \%$ and $97.8 \%$, identity match to $H$. microstoma AJ287525. The single sequence obtained for the $28 \mathrm{~S}$ region (5' and 3'strands of 1,171 bps (KU840386)) produced a $99.7 \%$ identity match to Hymenolepis sulcata GU166277.

A phylogenetic tree constructed from $18 \mathrm{~S}$ and $28 \mathrm{~S}$ sequences placed the tapeworm in the clade that contains both Hymenolepis nana and Hymenolepis microstoma (H. nana-H. microstoma clade) with over 95\% support (Figure 1). A tree constructed from18S sequences alone also placed the sample in the $H$. nana-H. microstoma clade with over $95 \%$ support (Figure 2.). The tree constructed from $28 \mathrm{~S}$ sequences alone contained no H. nana samples (Figure 3). Although it gave strong support (> 95\%) for a clade including the sample and H. microstoma, this clade also contained other species (i.e. Rodentolepis fraterna, Rodentolepis straminea, Staphylocystis furcata and others) for which $18 \mathrm{~S}$ sequences were not available. Not surprisingly, we found the $28 \mathrm{~S}$ tree (Figure 3) resembled the tree produced by Haukisalmi et al. (2010) which placed the sample in the 'Rodentolepis' clade. Within this clade, the most closely 
related sequence to the sample was an unnamed Rodentolepis species (Accession ID: GU166239.1), which we found to have originated from a tapeworm found in the edible dormouse, Glis glis, that, like the dormouse (Muscardinus avellanarius), is a member of the rodent family Gliridae.

\section{Free-living dormice screening}

Screening for cestode parasites in free-living dormice commenced in 2009 and from 2009 to 2013 we screened 213 faecal samples from UK free-living dormice for the presence of cestode ova. Using microscopy, cestode eggs were detected in one free-living dormouse from Denbighshire, Wales, and one from Cheshire, England, in 2012. DNA was successfully extracted from both samples and two sequences were amplified for the ITS region (503bp (KU840380) and 666bp (KU840381) in length). The results produced a $99.8 \%$ and $100 \%$ identity matches to Rodentolepis straminea (JN258054).

\section{Discussion}

Our results suggest the cestode found in the 2009 captive dormouse is closely related to Hymenolepis microstoma or a Rodentolepis sp. that was found in a different Gliridae host (Haukisalmi et al. 2010). It is not Rodentolepis straminea or R.fraterna as original microscopy had shown (pers.com. RA Bray 2000). Both Hymenolepis and Rodentolepis are paraphyletic genera as presently defined (see current results and Haukisalmi et al. 2010), but molecular analyses with much greater representation of species are needed before natural groupings can be circumscribed. Currently available sequences represent a small minority of described tapeworm species, making it impossible to identify the sample more precisely using molecular data. For example, no member of the Rodentolepis clade, with the exception of $H$. microstoma, is represented by $18 \mathrm{~S}$ or ITS sequences on GenBank ${ }^{\circledR}$. The Rodentolepis sp. most closely matching the 2009 captive dormouse sample originated from a Gliridae host. Whilst this means the dormouse could be a natural host of the identified tapeworm, it is difficult to identify natural hosts within Gliridae species because of the great morphological diversity of parasites (Haukisalmi et al. 2010). It is also important to 
note that tapeworm taxonomy does not necessarily reflect tapeworm phylogeny, and in most cases will not represent monophyletic groupings.

The fact that the parasite was detected in an animal originating from a captive bred collection, and was at a zoo during its quarantine period, suggests that the parasite could have been acquired from a domestic or exotic species, possibly even outside the order Rodentia.

Through the 28S phylogenetic tree we were able to recreate the tree of Haukisalmi et al. (2010). Using their systematics, the captive dormouse sample was also placed in the Rodentolepis clade. Parasites in this clade infect a range of mammal hosts including rodents, bats and shrews. Additionally, this clade contains H. nana, a rodent parasite that can infect humans (Haukisalmi et al. 2010; Ito 1997; Macnish et al. 2002). The alternative close phylogenetic match to the cestode identified in the captive dormouse of this study was Hymenolepis microstoma. As for other cestodes, it is known to infect domestic/laboratory mice (Mus musculus) and to require a beetle as an intermediate host for its development from egg to adult (Cunningham and Olson 2010). Only through use of flour beetles as intermediate hosts have any healthy rodents been artificially infected with H. microstoma (Nasher and Walkey 1981). Andreassen et al. (2004) have demonstrated that $H$. microstoma can develop into an adult without an intermediate host in artificially immunodeficient mice when a cestode egg is injected or ingested through coprophagy. This suggests the possibility of a direct lifecycle of $H$. microstoma in immunodeficient mice and lends support to the idea that $H$. microstoma could be phylogenetically closely related to $H$. nana, which is the only tapeworm known to not require an intermediate host in order to develop into an adult (Cuomo et al. 2009). Stress has been documented in animals undergoing reintroductions or translocations (Dickens et al. 2010, Parker et al. 2012). When the production of glucocorticoids due to chronic stress leads to immune system suppression (Dhabhar and McEwen 1997, Godbout 2006), it could be possible for Hymenolepis cestodes to cause health problems (Weinmann and Rothman 1967). However, for all three parasites discussed above (the unknown Rodentolepis sp. found on another Gliridae host [Haukisalmi et 
al. 2010], H. microstoma and the cestode from the 2009 captive animal) the health effects on dormice remain unknown.

From the screening of free-living dormice faecal samples we identified Rodentolepis straminea in two samples from the same two populations studied previously by Brown (2008). H. straminea has also been reported present in Essex in eight rodents specimens from three different species (Apodemus sylvaticus, Clethrionomys glareolus and Microtus agrestis), but not the dormouse (Nasher and Walkey 1981). Thus, this is the first confirmed report of $H$. straminea in dormice in the UK.

Low numbers of $H$. straminea were recorded by Nasher and Walkey (1981) in free-living bank voles (Clethrionomys glareolus) and short-tailed field voles (Microtus agrestis) in the UK, with a prevalence of infection of less than $2 \%$. Their experiments proved the susceptibility of infection, development and growth of high numbers of $H$. straminea cestode eggs in laboratory-bred field mice and two strains of Syrian hamster when using flour beetles as intermediate hosts. Immunocompetency appeared to play a role in allowing this parasite infection. The lack of host specificity observed by Nasher and Walkey (1981) for H. straminea has also been documented by Macnish et al. (2003) on Rodentolepis species. This demonstrates that, under certain circumstances, Hymenolepis and Rodentolepis species can be non-host specific. Whilst the exact transmission route of the cestode found in our captive individual remains unknown, the Nasher and Walkey (1981) and Macnish et al. (2003) findings add to the concern that the species found by this study, being closely related to Hymenolepis and Rodentolepis, could infect different species of the same order without an intermediate host, under certain circumstances. This means releasing individuals carrying a presumed non-native parasite could put the native fauna at risk, including nondormouse species.

Therefore, due to the lack of information regarding the health effects on dormice of the parasites discussed, in combination with finding different cestode species in the captive versus free-living 
population, we recommended the continued elimination of the parasites from captive dormice prior to reintroduction.

\section{Conclusion}

Through the use of molecular identification, we found that a cestode derived from a captive population of dormice destined for reintroduction was different from cestodes known to be endemic in free-living dormice populations in the UK. Whilst similar to the mouse bile-duct tapeworm Hymenolepis microstoma and to a Rodentolepis sp. found in Gliridae hosts, sequence differences are sufficient to rule out conspecificity. Our finding may well represent a known (i.e. described) tapeworm species that is simply not represented in GenBank ${ }^{\circledR}$. The use of molecular tools, especially in cases in which identification via morphology is problematic, can improve information acquisition and reduce uncertainty regarding the best management decision. To be most effective, however, a far greater representation of potential helminth pathogens, as well as other infectious agents, must be added to public sequence databases. Ideally these sequences should be linked to individual specimens, rather than species, in order to correlate their molecular and morphological signatures and prevent issues relating to future taxonomic revisions. Molecular work used for identification of specific pathogens, in conjunction with the use of disease risk analysis methods (Sainsbury et al. 2012) can help reduce the risk of disease spread in a free-living population due to an exotic pathogen introduction.

Conflict of Interest: The authors declare that they have no conflict of interest. 


\section{References}

Andreassen J, Ito A, Ito M, Nakao M, Nakaya K (2004) Hymenolepis microstoma: direct life cycle in immunodeficient mice. Journal of Helminthology 78:1 1-5

Benson DA, Karsch-Mizrachi I, Clark K, Lipman DJ, Ostell J, Sayers EW (2012) GenBank. Nucleic Acids Research, 40(Database issue) D48-53

Bright P, Morris P and Mitchell-Jones T (1996) The Dormouse Conservation Handbook. English Nature, Peterborough

Bright P, Morris P and Mitchell-Jones T (2006) The Dormouse Conservation Handbook. $2^{\text {nd }}$ edition. English Nature, Peterborough

Brown (2008) Unpublished. An investigation of intestinal parasites in Common Dormice (Muscardinus avellanarius): What types of parasites are found, and do parasites differ in wild and reintroduced populations? BSc thesis. University of Liverpool, UK

Carter I (2001) The Red Kite. Arlequin Press, Chelmsford, UK

Cunningham, AA (1996) Disease risks of wildlife translocations. Conservation Biology 349-353

Cunningham LJ, Olson PD (2010) Description of Hymenolepis microstoma (Nottingham strain): a classical tapeworm model for research in the genomic era. Parasite Vectors 3:123 
Cuomo MJ, Noel LB, White DB (2009) Diagnosing medical parasites: a public health officers guide to assisting laboratory and medical officers. Air Education and Training Command Randolph AFB, Tx.

Dhabhar FS, Mcewen BS (1997) Acute stress enhances while chronic stress suppresses cell-mediated immunity in vivo: A potential role for leukocyte trafficking. Brain, Behavior, and Immunity 11:4 286-306

Dickens, MJ, Delehanty DJ, Romero LM (2010) Stress: an inevitable component of animal translocation. Biological Conservation 143: 6 1329-1341

Forder V (2006) Reintroduction. Dormouse captive breeding fact sheet Wildwood Trust, Canterbury Godbout JP, Glaser R (2006) Stress-induced immune dysregulation: implications for wound healing, infectious disease and cancer. Journal of Neuroimmune Pharmacology 1:4 421-427

Gomez A, Nichols ES, Perkins SL (2012) Parasite conservation, conservation medicine, and ecosystem health. New Directions in Conservation Medicine: Applied Cases of Ecological Health 67-81

Haukisalmi V, Hardman LM, Foronda P, Feliu C, Laakkonen J, Niemimaa J, Henttonen, H, Jukka TL and Heikki H (2010) Systematic relationships of hymenolepidid cestodes of rodents and shrews inferred from sequences of 28S ribosomal RNA. Zoologica Scripta 39:6 631-641

Hill NJ, Rose K, Deane EM, Old JM (2007) Rodentolepis fraterna: the cause of mortality in a new host, the Spinifex hopping mouse (Notomys alexis). Australian Veterinary Journal 85:1 62-64

IUCN (1998) Guidelines for Re-introductions. Prepared by the IUCN/SSC Re-introductions Specialist Group, IUCN, Gland, Switzerland and Cambridge, UK 10pp 
Katoh K, Standley DM (2013) MAFFT multiple sequence alignment software version 7: improvements in performance and usability. Molecular Biology and Evolution 30:4 772-780

Kearse M, Moir R, Wilson A, Stones-Havas S, Cheung M, Sturrock S, Buxton S, Cooper A, Markowitz S, Duran C, Thierer T, Ashton B, Mentjies P, Drummond A (2012) Geneious Basic: an integrated and extendable desktop software platform for the organization and analysis of sequence data.

Bioinformatics 28:12 1647-1649

Littlewood DTJ, Olson PD (2001) Small subunit rDNA and the Platyhelminthes: signal, noise, conflict and compromise. Systematics Association Special Volume 60:262-278

Lymbery AJ, Morine M, Kanani HG, Beatty SJ, Morgan DL (2014) Co-invaders: The effects of alien parasites on native hosts. International Journal for Parasitology: Parasites and Wildlife 3:171-177

Macnish MG, Morgan-Ryan UM, Monis PT, Behnke JM, Thompson RCA (2002) A molecular phylogeny of nuclear and mitochondrial sequences in Hymenolepis nana (Cestoda) supports the existence of a cryptic species. Parasitology 125:567-575

Macnish MG, Ryan UM, Behnke JM, Thompson RCA (2003) Detection of the rodent tapeworm Rodentolepis (=Hymenolepis) microstoma in humans. A new zoonosis? International Journal for Parasitololy 33:10 1079-1085

Mitchell-Jones AJ \& White I (2009) Using reintroductions to reclaim the lost range of the dormouse, Muscardinus avellanarius, in England. Folia Zoology 58:3 341-348 
Nasher AK and Walkey M (1981) The Biology of Hymenolepis straminea (Cestoda; Cyclophillidaea) in the definitive host. Journal of the College of Science, University of Riyadh 12:1 189-201

Oldroyd BP (1999) Coevolution while you wait: Varroa jacobsoni, a new parasite of western honeybees Trends in Ecology and Evolution 14:8 312

Olson PD, Poddubnaya, LG, Littlewood, DTJ, Scholz T (2008) On the position of Archigetes and its bearing on the early evolution of the tapeworms. Journal of Parasitology 94:4 898-904

Parker KA, Dickens MJ, Clarke RH, Lovegrove TG (2012) The theory and practice of catching, holding, moving and releasing animals. In, PJ Seddon (Eds.), Reintroduction Biology: integrating science and management pp. 105-137. Oxford, UK: Blackwell Publishing Ltd.

Peniche G and Sainsbury AW (2014) Dormice Disease Risk Management and Post Release Health Surveillance April 2015-2016 Protocol, London, UK

Price MRS (1989) Animal re-introductions: the Arabian oryx in Oman. Cambridge University Press

Sainsbury AW, Deaville R, Lawson B, Cooley WA, Farelly SSJ, Stack MJ, Duff DP, McInnes CJ, Gurnell J, Russell PH, Rushton SP, Pfeiffer DU, Nettleton P, Lurz PWW (2008) Poxviral disease in red squirrels Sciurus vulgaris in the UK: spatial and temporal trends of an emerging threat. Ecohealth 5:3 $305-316$

Sainsbury AW, Armstrong DP \& Ewen, JG (2012) Methods of disease risk analysis for reintroduction programmes. In, PJ Seddon (Eds.), Reintroduction Biology: integrating science and management pp. 336359. Oxford, UK: Blackwell Publishing Ltd. 
Soorae PS (2008) The IUCN position statement on translocation of living organisms. In P. S. Soorae (Eds.), Global Re-introduction Perspectives: Re-introduction Case-studies from Around the Globe pp. 266-284. Abu Dhabi, United Arab Emirates: International Union for the Conservation of Nature /Species Survival Commission Re-introduction Specialist Group

Seddon PJ, Armstrong DP \& Maloney RF (2007) Developing the science of reintroduction biology. Conservation Biology 21:2 303-312

Stamatakis A (2006) RaxML-VI-HPC: maximum likelihood-based phylogenetic analyses with thousands of taxa and mixed models. Bioinformatics 22:21 2688-90

Toone WD, Wallace MP (1994) The extinction in the wild and reintroduction of the California condor (Gymnogyps californianus). In, ATC Feistner (Eds.), Creative Conservation pp. 411-419. Netherlands: Springer

Vaucher C, Beveridge I \& Spratt DM (1984) Cestodes du genre Hymenolepis Weinland 1858 (sensu lato) parasites de marsupiaux australiens et description de cinq especes nouvelles. Revue Suisse de Zoologie $91: 2443-458$

Viggers KL, Lindenmayer DB \& Spratt DM (1993) The importance of disease in reintroduction programmes. Wildlife Research 20:5 687-698

Walker SF, Bosch J, James TY, Litvintseva AP, Oliver-Valls AP, Piña S, García G, Rosa GA, Cunningham AA, Hole S, Griffiths R, Fisher MC (2008) Invasive pathogens threaten species recovery programs. Current Biology 18:853-854 
Weinmann CJ \& Rothman AH (1967) Effects of stress upon acquired immunity to the dwarf tapeworm, Hymenolepis nana. Experimental Parasitology 21:1 61-67

White I (2012) The National Dormouse Monitoring Programme in Britain. Peckiana 8:103-107

Woodford MH \& Rossiter PB (1993) Disease risks associated with wildlife translocation projects. Revue Scientifique et Technique (International Office of Epizootics) 12:1 115-135

\section{Supplementary Material}

All scripts used to perform the phylogenetic analysis can be found here:

https://github.com/DomBennett/Project-dormouse 
Table1. Primers used for the amplification of cestodes ova from (Muscardinus avellanarius) faecal samples. ITS1 (Macnish et al. 2002), 18S and 28S various regions (Littlewood and Olson 2001).

\begin{tabular}{|c|c|c|}
\hline & Name & Definition (5'-3') \\
\hline \multicolumn{3}{|r|}{ ITS1 region Primers } \\
\hline 1 & F3 & GCGGAAGGATCATTACACGTTC \\
\hline 2 & R3 & GCTCGACTCTTCATCGATCCACG \\
\hline \multicolumn{3}{|r|}{$18 \mathrm{~S}$ region Primers } \\
\hline 1 & $930 \mathrm{~F}$ & GCATGGAATAATGGAATAGG \\
\hline 2 & Cestode 6 & ACGGAAACCTTGTTACGACT \\
\hline 3 & $600 \mathrm{~F}$ & GGTGCCAGCAGCCGCG \\
\hline 4 & A27 & CCATACAAACGTCCCCGCCTG \\
\hline 5 & WormA & GCGAATGGCTCATTAAATCAG \\
\hline 6 & $1270 \mathrm{R}$ & CCGTCAATTCCTTTAAGT \\
\hline \multicolumn{3}{|r|}{$28 \mathrm{~S}$ region Primers } \\
\hline 1 & $300 \mathrm{~F}$ & CAAGTACCGTGAGGGAAAGTTG \\
\hline 2 & $400 \mathrm{R}$ & GCAGCTTGACTACACCCG \\
\hline
\end{tabular}


Figure 1. Species ML tree of all BLAST retrieved sequences of the order Cyclophillidae and dormouse amplified sequences of 18S (KU840383, KU840384, KU840385) and 28S (KU840386). Sequences were combined into a single supermatrix by matching sequences by species name. Bootstrap support is denoted by dots on node (black - 95\%, dark-grey $-90 \%$, white $-75 \%$ ). The captive dormouse sample sits in the H. nana-H. microstoma clade.

Figure 2. Sequence ML tree of all BLAST retrieved sequences of the order Cyclophillidae and dormouse amplified sequences of 18S (KU840383, KU840384, KU840385). Sequences were combined into a single supermatrix by matching sequences by accession ID. Bootstrap support is denoted by dots on node (black $-95 \%$, dark-grey $-90 \%$, white $-75 \%$ ). The captive dormouse sample sits in the H. nana-H. microstoma clade.

Figure 3. Sequence ML tree of all BLAST retrieved sequences of the order Cyclophillidae and dormouse amplified sequences of 28S (KU840386). Sequences were combined into a single supermatrix by matching sequences by accession ID. Bootstrap support is denoted by dots on node (black - 95\%, darkgrey $-90 \%$, white $-75 \%$ ). The dormouse sample sits in the Rodentolepis clade. 